\section{The American Association for Thoracic Surgery}

\section{Registration and Housing for AATS Week 2016 Is Now Available}

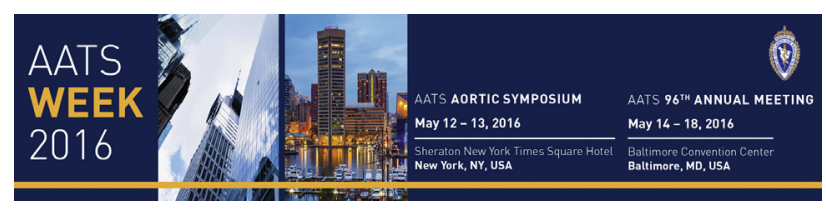

Register for AATS Week 2016 and receive a \$100 discount!

Aortic Symposium

May 12-13, 2016

New York, NY

Course Directors

Joseph S. Coselli

Steven L. Lansman

96th Annual Meeting

May 14-18, 2016

Baltimore, MD

President \& Annual Meeting Chair

Joseph S. Coselli

Annual Meeting Co-Chairs

Charles D. Fraser

David R. Jones

\section{Annual Meeting Registration Packages}

Allied Health Package includes registration for the Saturday Courses, Sunday Symposium, and the 96th Annual Meeting (Monday-Wednesday). Registration completed before March 25, 2016, is only $\$ 400$ and on or after March 26,2016 , is $\$ 500$.

Resident/Fellow and Medical Student Package includes registration for the Saturday Courses, Sunday Symposium, and the 96th Annual Meeting (Monday-Wednesday). Registrations completed before March 25, 2016, are able attend at no charge. After March 26, 2016, registration will be $\$ 300$.

Saturday Courses and Sunday Symposium Registration Register for a Saturday course and/or a Sunday symposium and you will have access to all other courses/symposia taking place that same day. Please note registration for the Saturday courses and/or Sunday symposium is separate from the Annual Meeting registration rate.

For more information regarding registration, housing and preliminary programs, please visit www.aats.org/ aatsweek

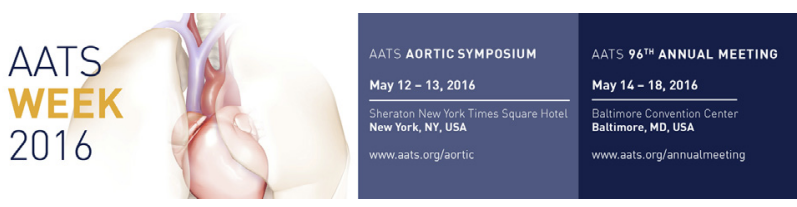

\section{The AATS Graham Foundation}
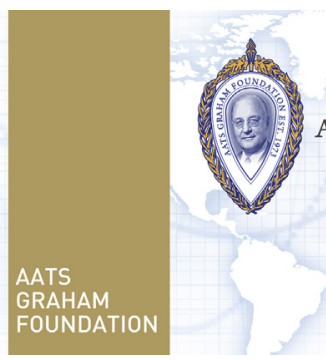

\title{
JTCVS Articles
}

The American Association for Thoracic Surgery and the AATS Graham Foundation is proud to announce that the following awards are open for applications. Eligibility requirements and application details can be found on the AATS award page

http://aats.org/research/grants.cgi and the Graham Foundation's activity page at http://aatsgrahamfoundation.org/activities.cgi.

Every Heartbeat Matters Valve Fellowship Sponsored by Edwards Lifesciences Foundation: Funds improved heart valve disease knowledge and skill training for surgeons around the world who treat individuals with limited access to health care. Surgeons may apply for up to three months of study. Deadline: February 15, 2016

F. Griffith Pearson Fellowship: Supports surgeons who have finished their residencies to advance their clinical techniques at a North American host institute. Each fellow receives $\$ 3,500$ to defray living expenses during four to six weeks of training. Deadline: January 15, 2016

Fellowship for Advanced Minimally Invasive Thoracic Surgery Sponsored by Ethicon: Offers North American young CT surgeons and their surgical teams the opportunity 